\title{
The improvement of high-temperature oxidation of Ti-50Al by anodic coating in the phosphoric acid
}

\author{
Mu-Rong Yang a, S.K. Wu ${ }^{\text {b,* }}$ \\ ${ }^{a}$ Department of Materials Science and Engineering, Tatung University, Taipei 104, Taiwan \\ ${ }^{\mathrm{b}}$ Institute of Materials Science and Engineering, National Taiwan University, Taipei 106, Taiwan
}

Received 21 June 2001; received in revised form 19 October 2001; accepted 23 October 2001

\begin{abstract}
The high temperature cyclic oxidation resistance of Ti-50Al can be improved by anodic coating in phosphoric acid aqueous solution $\left(4 \mathrm{wt} \% \mathrm{H}_{3} \mathrm{PO}_{4}\right)$ at $18^{\circ} \mathrm{C}$. Sparking occurs sporadically on the surface as the voltage is over $300 \mathrm{~V}$ and the instantaneous current density after $45 \mathrm{~min}$ of anodization increases with increasing voltage. The anodic films are amorphous and contain substantial amount of phosphorus. Cyclic oxidation test indicates that the anodization can remarkably reduce the oxidation in air at $800^{\circ} \mathrm{C}$ and the improvement increases with increasing anodizing voltage up to $400 \mathrm{~V}$, at which the parabolic oxidation rate constant can be reduced to about $1 / 600$ of that for as-homogenized Ti-50Al. Raman spectra show that the anodic film can slow down the formation of rutile and $\alpha-\mathrm{Al}_{2} \mathrm{O}_{3}$ during oxidation. The doping effect of phosphorus ions in titanium oxide accounts for the improvement of high temperature oxidation of Ti-50Al. (C) 2002 Acta Materialia Inc. Published by Elsevier Science Ltd. All rights reserved.
\end{abstract}

Keywords: Ti-50Al intermetallics; Anodization; Phosphoric acid; Cyclic oxidation

\section{Introduction}

The $\gamma$-titanium aluminides have been investigated for aerospace application and gas-turbine industry due to their excellent specific strength at high temperature $[1,2]$. However, the limited ductility at room temperature and the insufficient oxidation resistance at temperatures above $750^{\circ} \mathrm{C}$ pose a bottleneck to successful applications for years $[3,4]$.

* Corresponding author. Tel.: +886-2-2363-7846; fax: +8862-2363-4562.

E-mail address: skw@ccms.ntu.edu.tw (S.K. Wu).
Although alloying design and microstructural control can increase the room temperature ductility of $\gamma$-TiAl up to $4 \%$ [4], most of alloyed elements, except $\mathrm{Nb}[5,6]$, Mo [5,6] and Sb [7] can deteriorate the oxidation resistance. Alloyed $\gamma$-TiAl suffers from good balance between specific mechanical properties and sufficient oxidation resistance. Hence, the surface modifications, such as overlayer coatings [8-15], ion implantation [16-18] and preoxidation $[19,20]$, are often employed to enhance the oxidation resistance of $\gamma$-TiAl without altering its bulk properties. The current promising methods for barrier coatings on $\gamma$-TiAl alloys against high temperature oxidation include pre-oxidizing in pure oxygen $[19,20]$, forming $\mathrm{Al}_{3} \mathrm{Ti}$ layer by pack- 
cementation aluminizing [8], air-plasma-spraying $\mathrm{ZrO}_{2}-\mathrm{Ni}-4.5 \mathrm{wt} \% \mathrm{Al}$ coatings [9], forming chromium plate by electrolytic method [10], CVDdepositing $\mathrm{Al}_{2} \mathrm{O}_{3}$ films [11], boronizing by packsintering with $\mathrm{B}_{4} \mathrm{C}$ and/or $\mathrm{Na}_{2} \mathrm{~B}_{4} \mathrm{O}_{7}$ powder [12], coating $\mathrm{Si}_{3} \mathrm{~N}_{4}$ by ion-beam-enhanced deposition [13], coating M-CrAlY and/or $\mathrm{Al}_{2} \mathrm{O}_{3}$ mixture by plasma spray methods [14] and coating aluminosilicate glass by $\mathrm{SiO}_{2}$ and $\mathrm{Al}_{2} \mathrm{O}_{3}$ mixture [15]. However, improvement for the cyclic oxidation is limited due to the poor adhesion of these barrier coatings to the substrate, the misfit of thermal expansion coefficients between the coatings and substrate, and/or the intrinsic brittleness of the coatings. Extensive works have endeavored to enhance the oxidation resistance of $\gamma$-TiAl by ion implantation. The ion beam includes elemental species which can promote alumina $\left(\mathrm{Al}_{2} \mathrm{O}_{3}\right)$ formation, such as $\mathrm{Nb}, \mathrm{P}, \mathrm{Cl}, \mathrm{Al}, \mathrm{Mo}, \mathrm{Si}, \mathrm{Cr}, \mathrm{Ar}, \mathrm{B}, \mathrm{N}$ and $\mathrm{O}$ [16-18]. Among them, the most promising species are phosphorus ion and $\mathrm{Nb}$ ion. However, the ion implantation requires costly and sophisticated equipment. Besides, the conformal coverage is an intrinsic drawback for workpieces with complex shapes.

Microalloying of phosphorus in $\gamma$-TiAl alleviates its high temperature oxidation [21]. Moreover, Retallick et al. have employed painting phosphoric acid onto the $\gamma$-TiAl and subsequent calcining to substantially improve the oxidation resistance at $800^{\circ} \mathrm{C}$ by reducing two orders of magnitude in oxidation rate [22]. Although this process has the merits of good conformal coverage, low facility cost and easy operation, yet time-consuming and poor appearance after treatment leave space for further improvement. Phosphoric acid is a well-known solution for anodizing aluminum alloys [23]. In addition, for the passivation of the anodized titanium alloys, the phosphate-based materials give by far the best results among various electrolytes [24]. The beneficial characteristic of phosphorus against oxidation resistance and the satisfactory performance of titnaium and aluminium alloys anodizied in phosphoric acid solution reveal that anodic coating of $\gamma$-TiAl in phosphoric acid solution seems to be feasible and deserves to be investigated.

\section{Experimental procedures}

The Ti-50Al was prepared from titanium (99.7\%) and aluminum (99.98\%) using a vacuum/argon tungsten arc furnace. The ingots were homogenized at $1150^{\circ} \mathrm{C}$ in vacuum for $75 \mathrm{~h}$ and furnace-cooled to room temperature. The single $\gamma$-TiAl, confirmed by X-ray diffraction and metallographic observation (optical microscopy and scanning electron microscopy), excludes the possibility of the presence of $\alpha_{2}-\mathrm{Ti}_{3} \mathrm{Al}$ in the ingot. The homogenized ingots were sectioned into $0.8 \times 1.0 \times 13\left(\mathrm{~mm}^{3}\right)$ by Buehler Iosmet low speed diamond saw. The surface was mechanically polished through a standard metallographic procedure to a final polishment of $0.3 \mu \mathrm{m}$ alumina and cleaned ultrasonically in acetone and ethanol for 5 min sequentially and then rinsed with deionized water.

The dimension of the specimen and the exposed area for anodization were delineated by a 3-M tape and measured to an accuracy of $0.1 \mathrm{~mm}$ by an optical microscope. The polished specimens were anodized with various constant direct current (DC) voltages in the electrolytic solution of $4 \mathrm{wt} \%$ phosphoric acid (Merck Co.) at $18 \pm 0.5^{\circ} \mathrm{C}$ for $45 \mathrm{~min}$. The electrolytic solution was stirred continuously during anodization. The separation between the specimen and the counter-electrode (platinumcoated titanium net) was $5 \mathrm{~cm}$. After anodization, the specimens were rinsed in running water for at least $30 \mathrm{~min}$.

The cyclic oxidation behaviors of anodized specimens were characterized by exposing the specimens to hot air $\left(800^{\circ} \mathrm{C}\right)$ from a muffle furnace. They are regularly removed from the muffle furnace, then air cooled, weighed and returned to the $800^{\circ} \mathrm{C}$ furnace. The weight gains per exposed area $\left(\mathrm{mg} / \mathrm{mm}^{2}\right)$, weighed on an analytical balance to an accuracy of $\pm 10^{-3} \mathrm{mg}$, were used to evaluate the oxidation resistance.

The crystal structures of oxide scales were determined by using a grazing angle X-ray diffractometer (GXRD) with $\mathrm{CuK} \alpha$ radiation at 45 $\mathrm{kV}, 30 \mathrm{~mA}$ and $4^{\circ}(2 \theta) / \mathrm{min}$ scanning rate at a grazing angle of $4^{\circ}$. The microstructural observation was carried out by a Philips XL30 scanning electron microscope (SEM) equipped with the energy 
dispersive spectrometry (EDX). Depth profiles of the chemical composition of anodic coatings were determined by glow discharge optical spectroscopy (GDOS) [25].

Since titanium oxide is a strong Raman scatter [26], Raman spectra were used to characterize the oxide film in this study. The Raman spectra were recorded on a Renishaw system 2000 microRaman spectrometer with a He-Ne laser $(632.8 \mathrm{~nm}$ wavelength) or $\mathrm{Ar}^{+}$laser (514.5 $\mathrm{nm}$ wavelength) as the excitation source. With a $5-\mu \mathrm{m}$ exit slit width, the Raman spectral resolution was better than $\pm 1 \mathrm{~cm}^{-1}$. The laser power used was $8 \mathrm{~mW}$ for $\mathrm{He}-\mathrm{Ne}$ laser and $50 \mathrm{~mW}$ for $\mathrm{Ar}^{+}$laser. All Raman spectra were taken at room temperature.

\section{Results and discussion}

\subsection{Anodizing process of Ti-50Al specimen}

At the early stage of constant-voltage anodization of $\mathrm{Ti}-50 \mathrm{Al}$ in phosphoric acid at $18^{\circ} \mathrm{C}$, oxygen evolution takes place as bubbles attached on the surface of anode and increases with increasing the applied voltage. Therefore the removal of the bubbles is required for uniform anodic coating by interrupting the process after about $60 \mathrm{~s}$ anodization. Hereafter, the oxygen evolution on the surface of the anode (specimen) is not observed for the latter period of anodization if the applied DC voltage is below $350 \mathrm{~V}$. The thickness of the passive film should increase when the anodizing proceeds, as confirmed later, resulting in the decrease of the field strength [27]. Hence, the current density of anodization of Ti-50Al in phosphoric solution falls rapidly at the early stage and then decreases monotonically during the course of anodization, as shown in Fig. 1. As the applied voltage increases, the current intensity fluctuates more and more rapidly. If the applied voltage is over 350 $\mathrm{V}$, sparking breakdown occurs, i.e., the intensive sparks and oxygen evolution starts, and then both the sporadic sparks and oxygen evolution happen less intensively for the later period of anodization. For a higher anodizing voltage, such as $400 \mathrm{~V}$, the sparks occur very violently and oxygen evolution aggressively bursts into bubbles during the course of anodization. The anodic films formed at the voltage over $350 \mathrm{~V}$ are found to be tarnished.

Fig. 2 shows the relationships between the applied voltage and the current density at the end (45 min) of the anodization in phosphoric acid at $18^{\circ} \mathrm{C}$. The final current densities increase with increasing the applied voltage and reach a maximum at around $225 \mathrm{~V}$. When the voltage is over $225 \mathrm{~V}$, the final current densities decrease with increasing the applied voltage. The ratio of applied voltage to current density roughly represents the resistance per unit area of anodic film since the resistance of the circuit is negligible in contrast to the high resistance of the passive anodic coating. It can be seen that the resistance per unit area considerably increases when the applied DC voltage is over $225 \mathrm{~V}$. The reduction in current density for the anodizing voltage higher than 225 $\mathrm{V}$ in Fig. 2 may be attributed to the fact that the increase of the resistance per unit area overwhelms the increase of the applied voltage. The final current density ranges from $9.6 \times 10^{-8} \mathrm{~mA} / \mathrm{mm}^{2}(60$ V) to $3.2 \times 10^{-7} \mathrm{~mA} / \mathrm{mm}^{2}(225 \mathrm{~V})$ in this study.

The weight gain per unit area after anodizing in phosphoric acid at $18^{\circ} \mathrm{C}$ for $45 \mathrm{~min}$ vs. the anodizing voltage is shown in Fig. 3. The weight gain per unit area increases with the increase in applied voltage and tends to level off when the applied voltage is above $300 \mathrm{~V}$. This may be associated with the electrical field-assisted dissolution and the existence of sparks on the surface during anodization, which may locally raise the temperature and increase the dissolution effect of phosphoric acid since phosphoric acid is a well-known electrolytic solution with solvent action [28]. The accelerated dissolution counterbalances the weight gain of anodizing oxidation and results in the leveling-off of the curve when the applied voltage is over $300 \mathrm{~V}$, as shown in Fig. 3.

\subsection{Microstructure of the anodic coatings}

Fig. 4 shows the plan-viewed morphologies of as-anodized Ti-50Al. The higher the voltage applied, the more the rugged surface formed. This indicates that solvent action of phosphoric acid occurs during anodization and confirms that the 


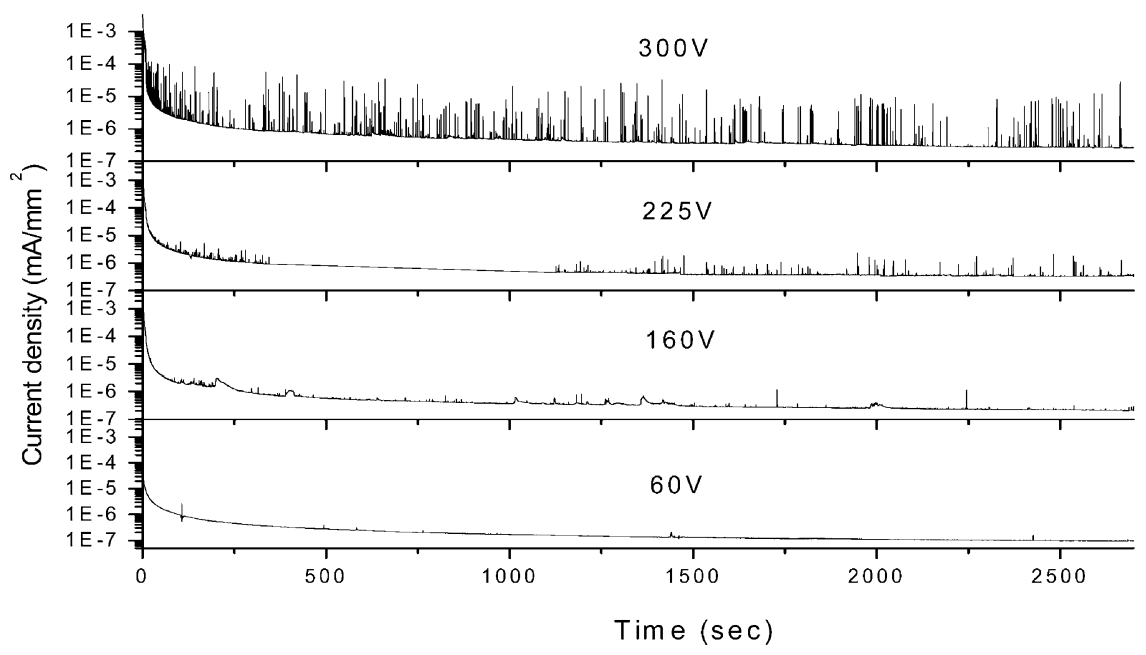

Fig. 1. The variation of current density with time under various anodizinig voltages in $4 \mathrm{wt} \%$ phosphoric acid at $18^{\circ} \mathrm{C}$.

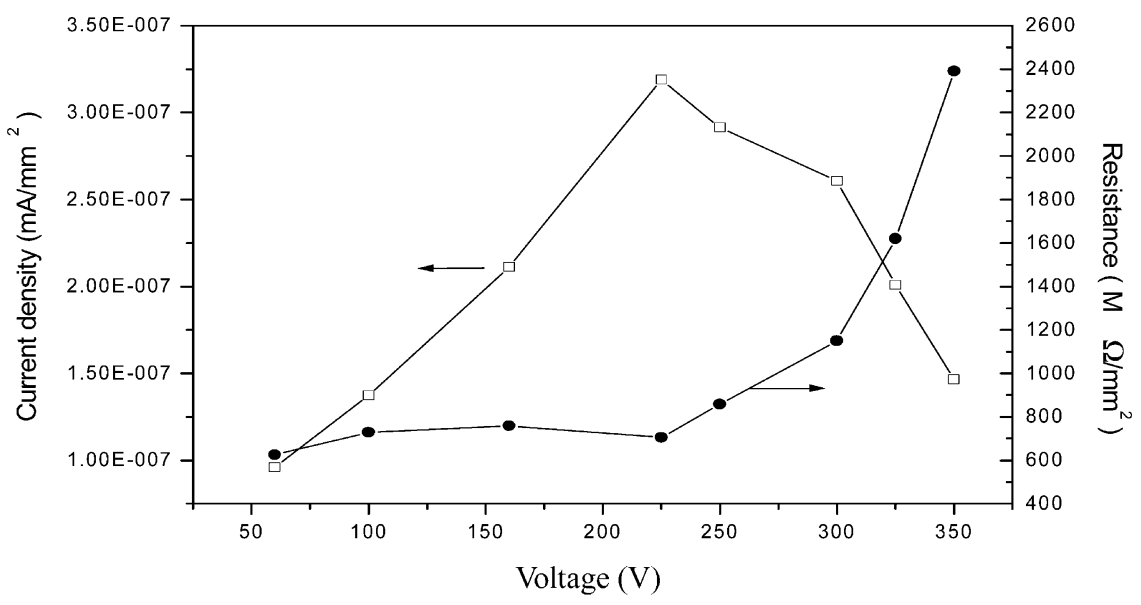

Fig. 2. Effect of anodizing voltage on the current density and resistance (per unit area) of anodized film.

increase in the anodized voltage can enhance the solvent action of phosphoric acid.

Fig. 5 demonstrates the depth profiles of elements $\mathrm{Ti}, \mathrm{Al}, \mathrm{O}, \mathrm{P}$ and $\mathrm{H}$ (in at.\%) of the anodic films formed at various DC voltages in $18^{\circ} \mathrm{C}$ phosphoric acid solution. In addition to oxygen, the anodization in phosphoric solution can bring into a significant concentration of phosphorus in the anodic film and the penetration depth of phosphorus also increases as the applied voltage increases. The content of titanium is less than that of aluminum in the anodic films. This implies that preferred solvent solution may occur. From Fig. 5, the thicknesses of the anodic film prepared at 160 , 300 and $400 \mathrm{~V}$ are evaluated as $0.23,0.65$ and $\approx 2$ $\mu \mathrm{m}$, respectively. That is, the thickness of the anodic film increases upon increasing the applied DC voltage. This result is in consistent with the SEM observation for the anodic coatings shown in Fig. 6(a) (300 V) and Fig. 6(b) (400 V). In Fig. $6(\mathrm{~b})$, for the rugged anodic coating prepared at 400 $\mathrm{V}$, the average thickness of its anodic film determined by GDOS is about $2 \mu \mathrm{m}$.

The GXRD patterns of the anodic films formed at various voltages in $18^{\circ} \mathrm{C}$ phosphoric acid solution are shown in Fig. 7 which shows that only 


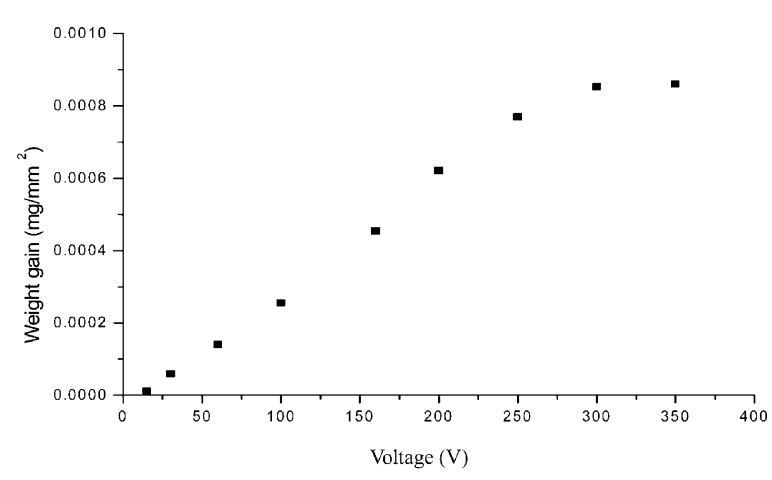

Fig. 3. Effect of anodizing voltage on the weight gains after anodization.

$\gamma$-TiAl diffraction peaks appear with superposed amorphous signals. In general, the sparking and accompanied gas breakdown of anodization usually result in the crystallization of the anodic films [29]. However, even for $400 \mathrm{~V}$ anodization in phosphoric acid solution, at which violent sparking occurs, the crystallization of anodic film on TiAl is not found. The anodic films prepared at higher DC voltages give more amorphous signals in GXRD patterns of Fig. 7. This is attributable to the fact that the higher the anodizing voltage, the more the thickness of anodic amorphous film, as confirmed in Fig. 5.

\subsection{The cyclic oxidation kinetics of Ti-50Al with the anodic coatings}

As-homogenized $\mathrm{Ti}-50 \mathrm{Al}$ loses its metallic luster within $5 \mathrm{~h}$ exposure in static air at $800^{\circ} \mathrm{C}$ and has serious scale spallation after about $35 \mathrm{~h}$ of oxidation. However, for Ti-50Al anodized in phosphoric acid, the anodic shinning color is more durable. The anodic coating formed at $300 \mathrm{~V}$ remains its original color luster even after $70 \mathrm{~h}$ cyclic exposure in static air at $800^{\circ} \mathrm{C}$.

Fig. 8 shows the cyclic oxidation kinetics in static air at $800^{\circ} \mathrm{C}$ for $\mathrm{Ti}-50 \mathrm{Al}$ which has been anodic-coated in the electrolyte of $4 \mathrm{wt} \%$ phosphoric acid at $18^{\circ} \mathrm{C}$ under various anodizing voltages for $45 \mathrm{~min}$. As mentioned above, the oxidation curve for as-homogenized Ti-50Al is so scattered due to the scale spallation. This implies that the scale adherence is not good and the oxide layer is very brittle and fragile. The oxidation curve of as-homogenized $\mathrm{Ti}-50 \mathrm{Al}$, measured by TGA is shown in Fig. 8, indicates that the oxidation rate does not completely obey the parabolic law in all periods of oxidation. However, if the specimen has been anodized in phosphoric acid, no scale spallation occurs during cyclic oxidation. The anodic film on the Ti-50Al adheres very well to the substrate. As shown in Fig. 8, the anodizing process in phosphoric acid can substantially reduce the oxidation rate of $\mathrm{Ti}-50 \mathrm{Al}$. Initially, the oxidation behavior of the anodized specimen seems to be quasi-linear and then gradually shifts toward the parabolic law. After about 10 hrs of oxidation, the parabolic oxidation law dominates the oxidation rate. The parabolic oxidation rate constant, $\mathrm{kp}$, can be calculated from the curve fitting of Fig. 8 and this constant can be used as a convenient index for comparing the oxidation resistance.

Fig. 9 plots the calculated $\mathrm{kp}$ value vs. applied $\mathrm{DC}$ voltage. For specimen anodized at $60 \mathrm{~V}, \mathrm{kp}$ is $0.00343 \mathrm{mg}^{2} / \mathrm{cm}^{4} \mathrm{~h}$, in contrast to $0.041 \mathrm{mg}^{2} / \mathrm{cm}^{4} \mathrm{~h}$ for as-homogenized Ti-50Al. The increase in anodizing voltage leads to the decrease in $\mathrm{kp}$, i.e., enhances the oxidation resistance of Ti-50Al. For the Ti-50Al specimen anodized at $400 \mathrm{~V}$ for 45 min, $\mathrm{kp}$ can be further reduced to 0.000068 $\mathrm{mg}^{2} / \mathrm{cm}^{4} \mathrm{~h}$, which is about $1 / 600$ of $\mathrm{kp}$ for as-homogenized Ti-50Al.

\subsection{Raman spectra of anodized Ti-50Al after cyclic oxidation}

Fig. 10 shows the $\mathrm{Ar}^{+}$laser-excited Raman spectra of the as-homogenized $\mathrm{Ti}-50 \mathrm{Al}$ after various durations of cyclic oxidation at $800^{\circ} \mathrm{C}$ in air. The characteristic rutile spectrum in this range are the peaks at $447 \mathrm{~cm}^{-1}(\mathrm{Eg})$ and $610 \mathrm{~cm}^{-1}(\mathrm{~A} 1 \mathrm{~g})$ [30]. It is evident that only rutile phase appears and its volume increases with the increase in oxidation time. To distinguish the crystal structure of alumina from rutile on the surface of Ti-50Al, the most suitable excitation source is the $\mathrm{He}-\mathrm{Ne}$ laser (632.8 $\mathrm{nm})$ [31]. The peaks at $1374 \mathrm{~cm}^{-1}$ and 1403 $\mathrm{cm}^{-1}$ of Fig. 11 are the characteristic Raman spectra of $\alpha-\mathrm{Al}_{2} \mathrm{O}_{3}$ [31], which is a spinel structure. Similar trends and phenomena are also found on $\mathrm{Ti}-50 \mathrm{Al}$ with anodic coating at $300 \mathrm{~V}$, as shown 


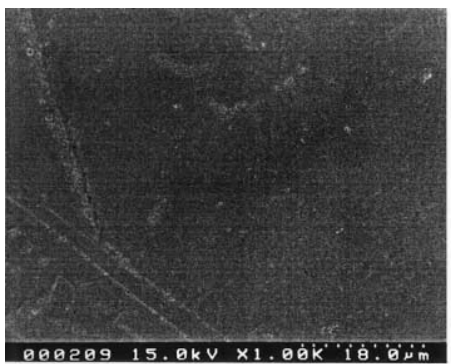

$60 \mathrm{~V}, 45 \mathrm{~min}$

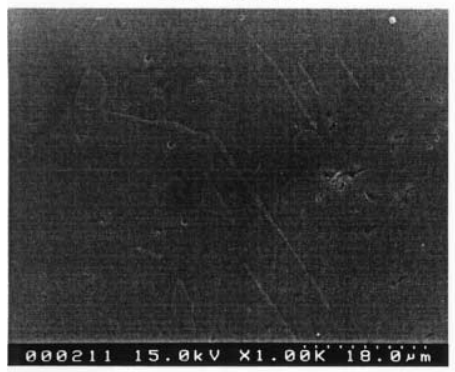

$160 \mathrm{~V}, 45 \mathrm{~min}$

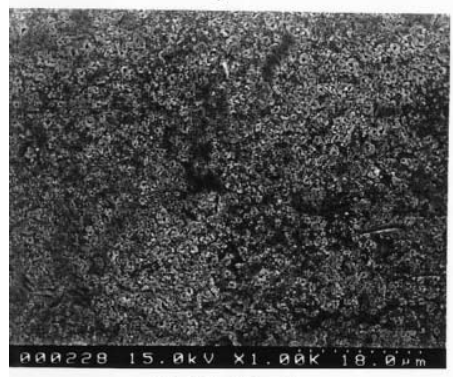

$225 \mathrm{~V}, 45 \mathrm{~min}$

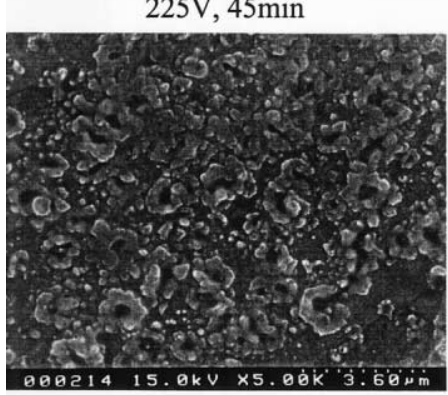

$225 \mathrm{~V}, 45 \mathrm{~min}$

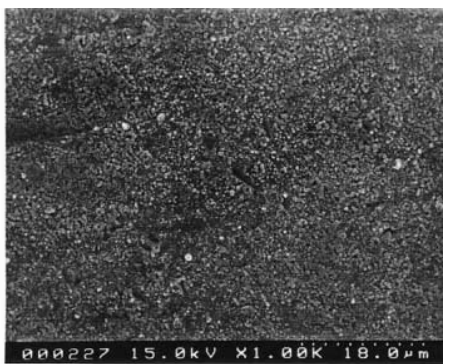

$250 \mathrm{~V}, 45 \mathrm{~min}$

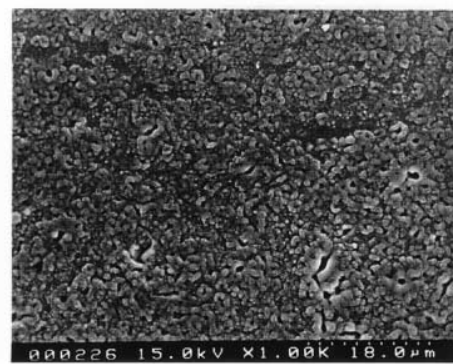

$300 \mathrm{~V}, 45 \mathrm{~min}$

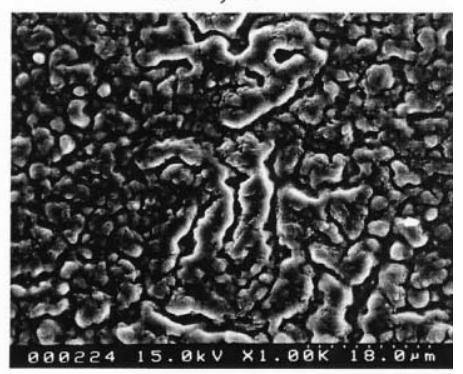

$350 \mathrm{~V}, 45 \mathrm{~min}$

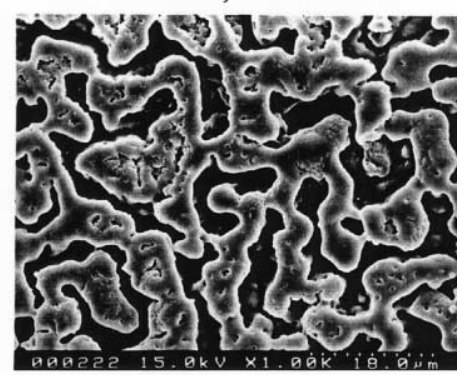

$400 \mathrm{~V}, 45 \mathrm{~min}$

Fig. 4. Plan-viewed morphologies of anodized Ti-50Al under various voltages for 45 min in 4 wt $\%$ phosphoric acid at $18^{\circ} \mathrm{C}$.

in Figs. 12 and 13, however, both the intensities of rutile and $\alpha-\mathrm{Al}_{2} \mathrm{O}_{3}$ are less than those of the as-homogenized $\mathrm{Ti}-50 \mathrm{Al}$. This indicates that the anodic film can slow down the formation of oxides during the oxidation. The peaks can be deconvoluted according to Raman spectra of the pure ana- tase, rutile and $\alpha-\mathrm{Al}_{2} \mathrm{O}_{3}$. The peaks at $392 \mathrm{~cm}^{-1}$ (B1g), $513 \mathrm{~cm}^{-1}$ (A1g-B1g) and $635 \mathrm{~cm}^{-1}(\mathrm{Eg})$ are associated with the Raman shifts of anatase [32]. The anodization by $300 \mathrm{~V}$ can not only slow down the transformation of amorphous oxide into crystalline oxide, but also inhibit the transform- 

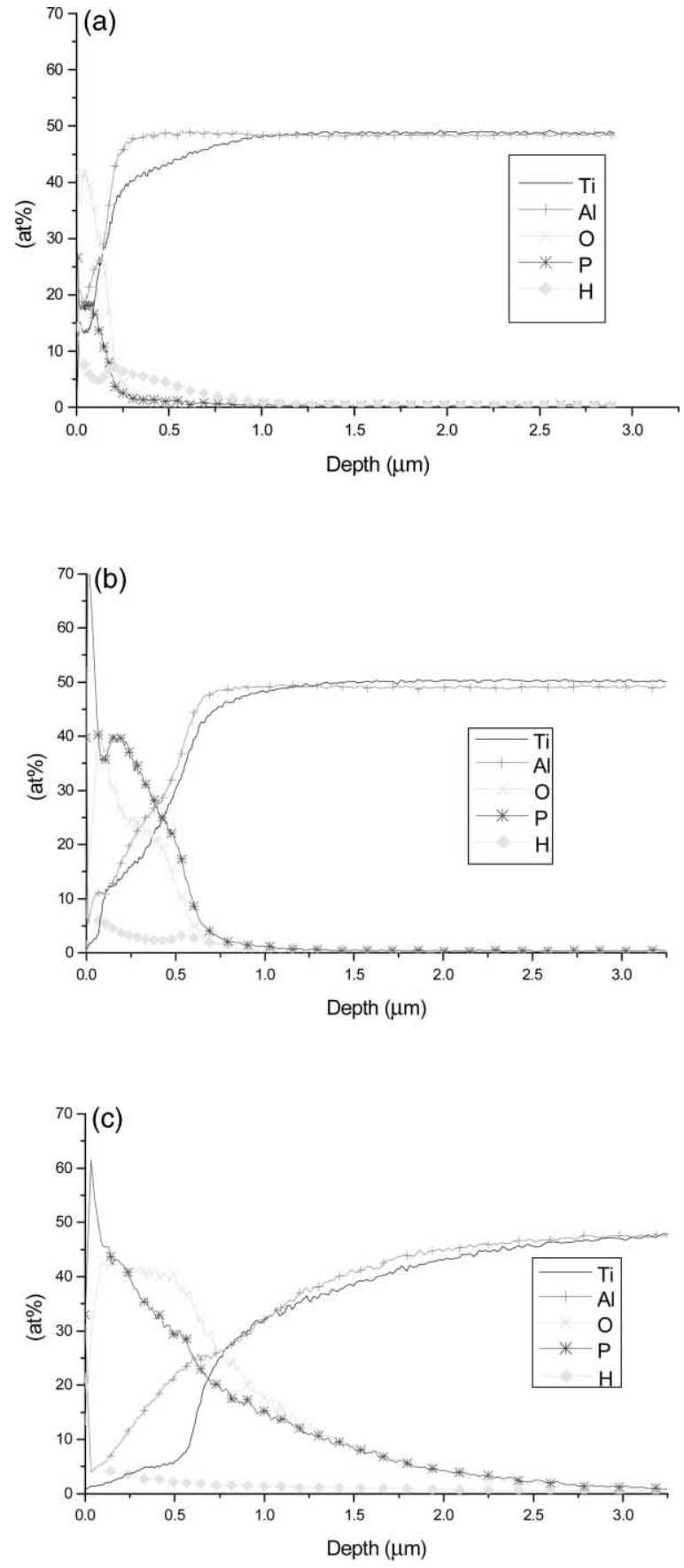

Fig. 5. Glow discharge optical spectra (GDOS) of the anodic films formed at different voltages (a) $160 \mathrm{~V}$, (b) $300 \mathrm{~V}$, (c) $400 \mathrm{~V}$. (a)

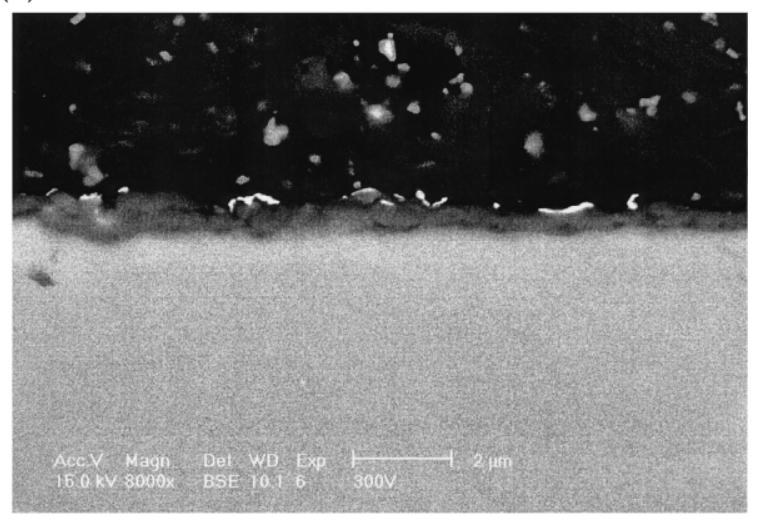

(b)

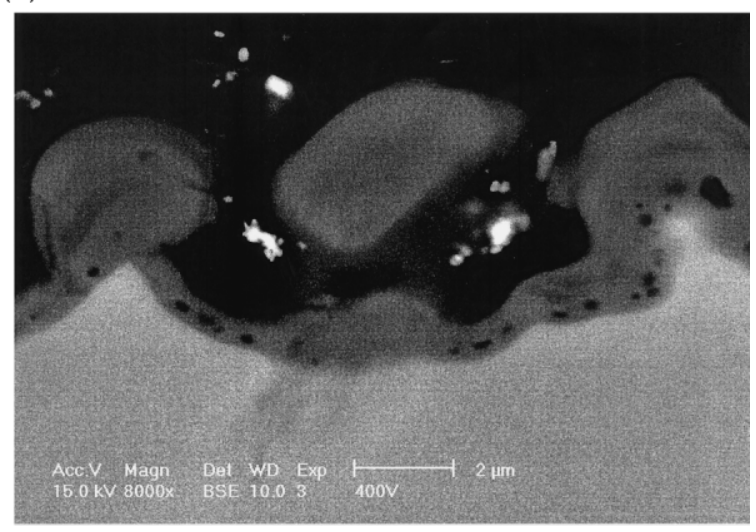

Fig. 6. The SEM cross-sectional morphologies of Ti-50Al with anodic coatings prepared at different DC voltages (a) 300 $\mathrm{V}$, (b) $400 \mathrm{~V}$.

ation of titatium oxide into the thermodyamic stable phase (rutile). At $400 \mathrm{~V}$, experimental results show that a substantial amount of anatase phase is still present even after the exposure in $800^{\circ} \mathrm{C}$ air for $70 \mathrm{~h}$. Obviously, $400 \mathrm{~V}$ anodic coating can further depress the formation of $\alpha-\mathrm{Al}_{2} \mathrm{O}_{3}$.

\subsection{The phosphorus effect on the improvement of high temperature oxidation of $\mathrm{Ti}-50 \mathrm{Al}$}

Titanium oxide is a well-known n-type semiconductor [33]. This is the main reason for the poor protectiveness against the oxidation resistance of $\gamma$-TiAl $[1,4]$. In this study, the introduction of a substantial amount of phosphorus into the anodic film is evidently shown in Fig. 5. Phosphate is a 


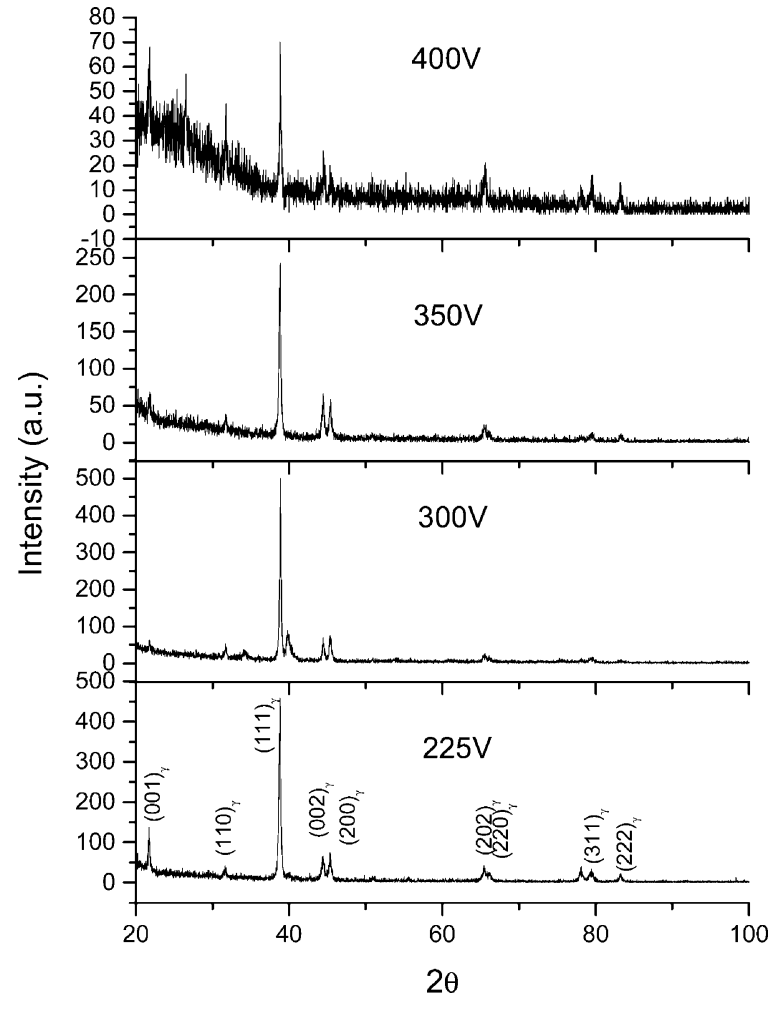

Fig. 7. The GXRD patterns at $4^{\circ}$ grazing angle of incidence of the anodic films formed at different voltages.

strong catalyst for the crystallization of anatase [34]. Anatase is a metastable phase which transforms exothermically and irreversibly to rutile. Moreover, the high dose of phosphorus doping in an anodic film can result in two effects: (1) The total impurity content can affect the transformation through the structure stuffing effect. Large quantities of impurities raise the transformation temperature. (2) The nature of the impurities appears to control the stoichiometry of the $\mathrm{TiO}_{2}$ and thus affects the oxygen vacancy concentration. Ions of valence greater than four, e.g., $\mathrm{P}^{5+}\left(3 S^{2} P^{3}\right)$, would correspondingly reduce the oxygen vacancy concentration and the transformation rate $[35,36]$. The disappearance of oxygen ion vacancies in titanium oxide reduces oxygen supply to the oxide/metal interface and enhances the protectiveness of titanium oxide. Hence, more phosphorus atoms in an anodic film, resulting from the increase in the anodizing DC voltage, will lead to a better oxidation resistance of $\gamma$-TiAl at high temperature. Regarding the oxidation investigation of $\gamma$-TiAl implanted a few 100 ppm phosphorus by high-resolution XRD method, Schumacher et al. [37] reported that the phosphorus doping of $\mathrm{TiO}_{2}$ can lower the diffusion rates of $\mathrm{Ti}$ and $\mathrm{Al}$ in the $\mathrm{TiO}_{2}$ lattices. This causes a change of the growth direction of the alumina partial layer from outward to inward growth, and reduces the oxygen diffusion rate simultaneously. Although the phosphorus concentration in the anodic film is much higher than that in the implanted layer, the model of phosphorus doping in $\mathrm{TiO}_{2}$ seems can also be applied to explain the significant improvement of high temperature oxidation of $\gamma$-TiAl observed in this study.

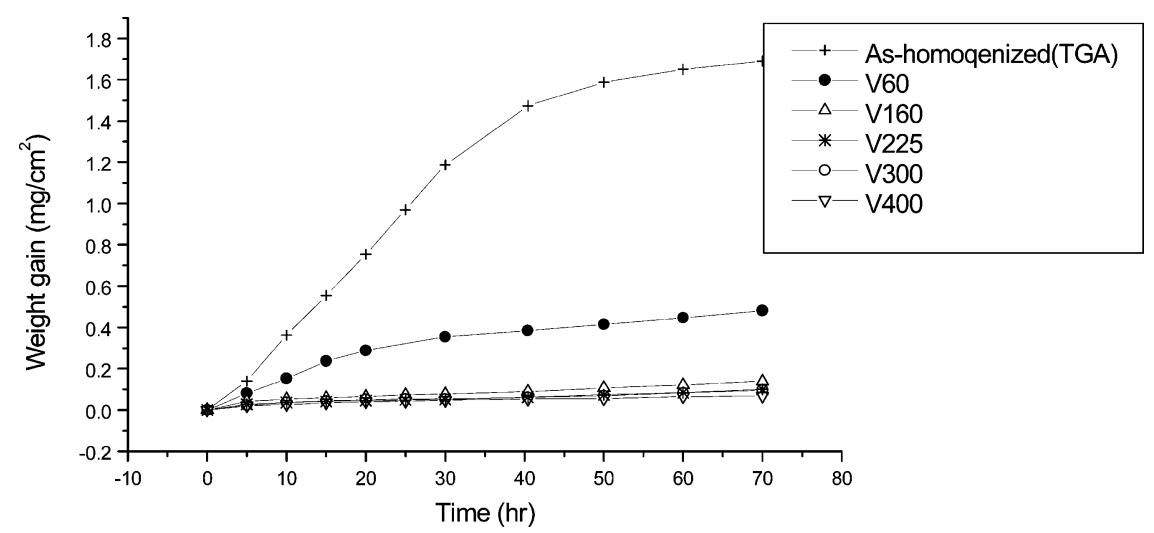

Fig. 8. The oxidation kinetics in static air at $800^{\circ} \mathrm{C}$ for Ti-50Al anodized in the electrolyte of 4 wt $\%$ phosphoric acid at $18^{\circ} \mathrm{C}$ under various anodizing voltages for $45 \mathrm{~min}$. 


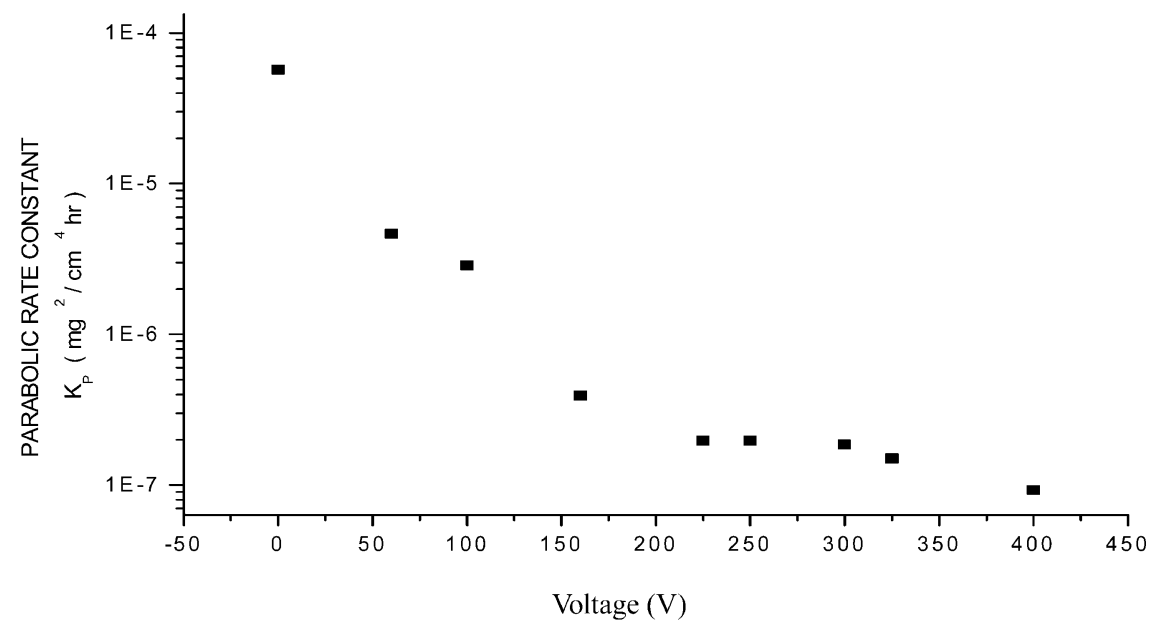

Fig. 9. Effects of anodizing voltage on oxidation resistance (parabolic rate constant $\mathrm{kp}$ ) of $\mathrm{Ti}-50 \mathrm{Al}$ in static air at $800^{\circ} \mathrm{C}$.

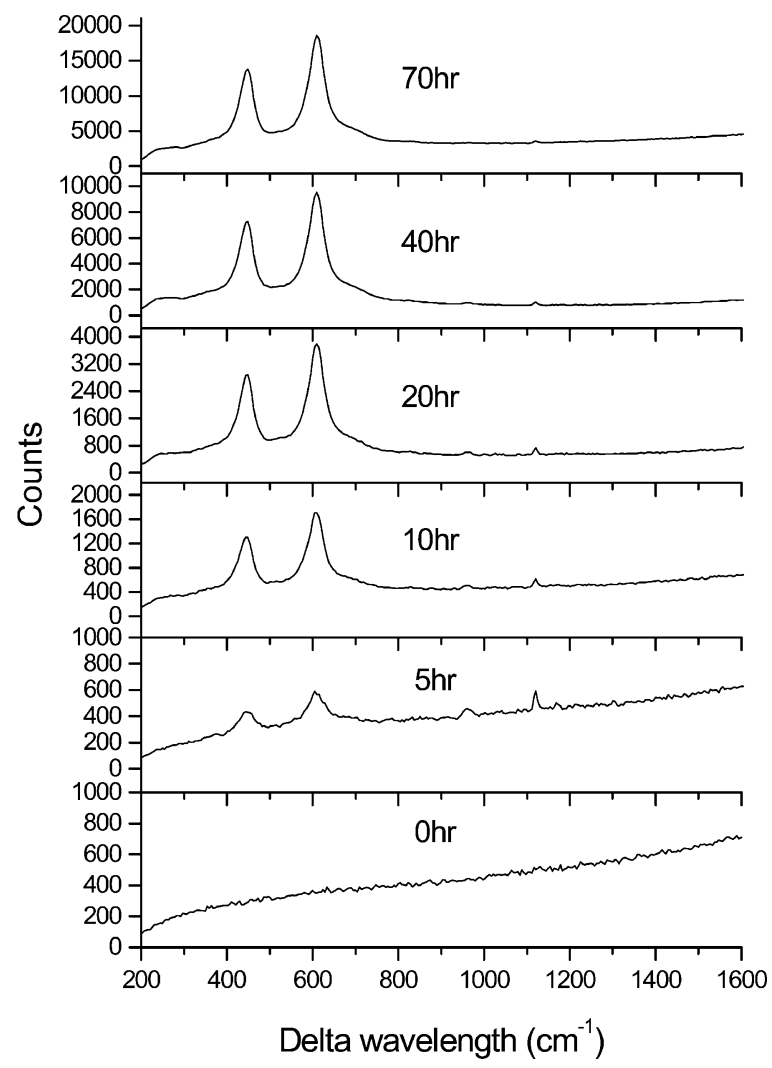

Fig. 10. The $\mathrm{Ar}^{+}$laser excited Raman spectra of the as-homogenized $\mathrm{Ti}-50 \mathrm{Al}$ after exposure in air at $800^{\circ} \mathrm{C}$ for various durations.

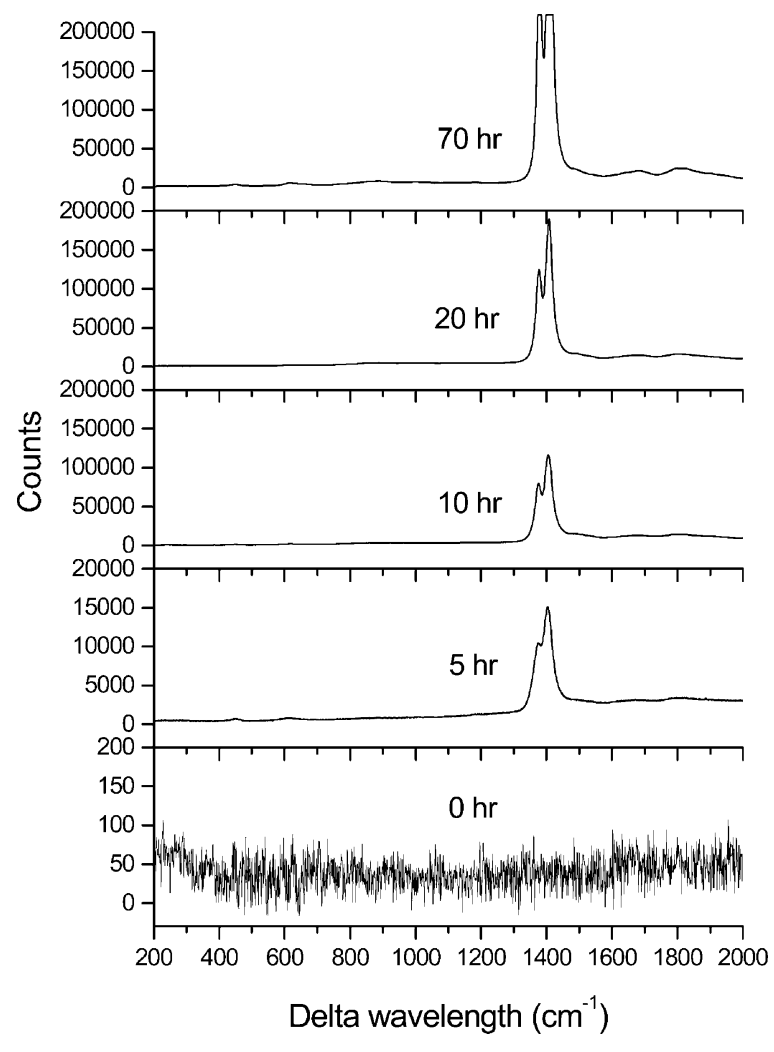

Fig. 11. The He-Ne laser excited Raman spectra of the ashomogenized $\mathrm{Ti}-50 \mathrm{Al}$ after exposure in air at $800^{\circ} \mathrm{C}$ for various durations. 


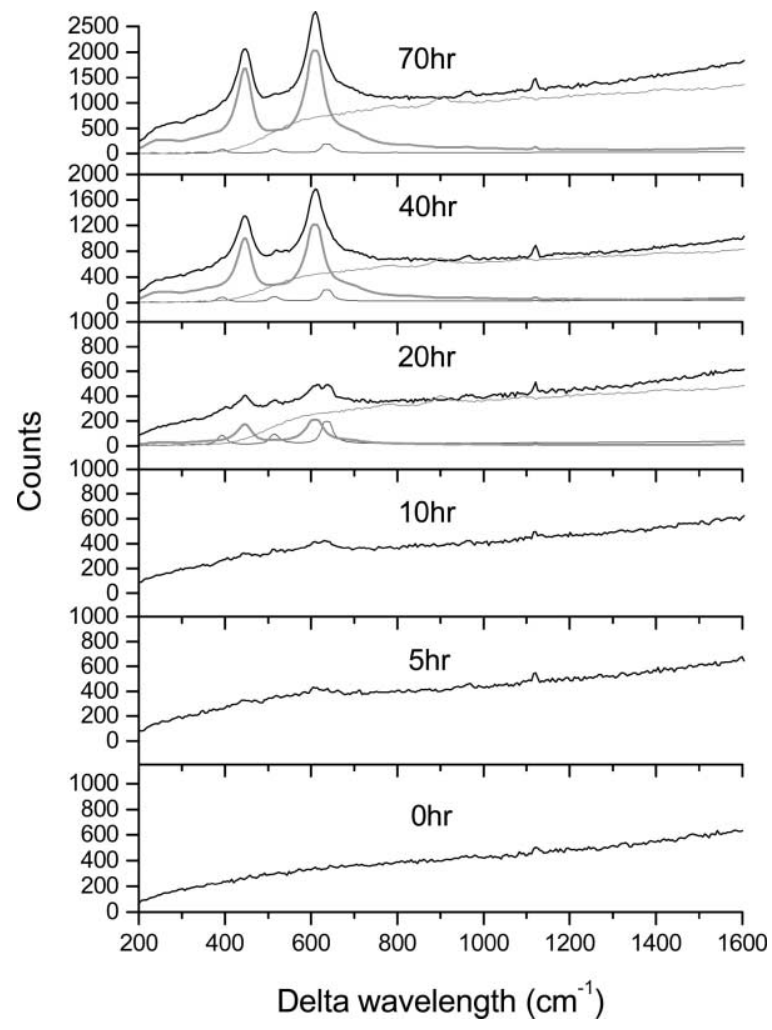

Fig. 12. The $\mathrm{Ar}^{+}$laser excited Raman spectra of the anodized $\mathrm{Ti}-50 \mathrm{Al}$ after the exposure in air at $800^{\circ} \mathrm{C}$ for various durations. Anodization was carried out at $300 \mathrm{~V}$.

\section{Conclusions}

The high temperature cyclic oxidation resistance of $\mathrm{Ti}-50 \mathrm{Al}$ can be improved by anodic coating in $4 \mathrm{wt} \%, 18^{\circ} \mathrm{C}$ phosphoric acid solution. The current density of anodization decreases monotonically during anodization under a constant voltage. The spark occurs sporadically on the specimens as the voltage is over $300 \mathrm{~V}$ and the instantaneous current density after $45 \mathrm{~min}$ of anodization increases with increasing the voltage. The $4 \mathrm{wt} \%$ phosphoric acid solution at $18^{\circ} \mathrm{C}$ has some solvent action during anodization, which leads to the fact that the higher the voltage is applied, the more the rugged surface it has. The anodic films are amorphous and contain substantial amount of phosphorus. Cyclic oxidation test at $800^{\circ} \mathrm{C}$ air indicates that the anodized $\mathrm{Ti}-$ $50 \mathrm{Al}$ can remarkably reduce the oxidation rate and the improvement increases with the increasing ano-

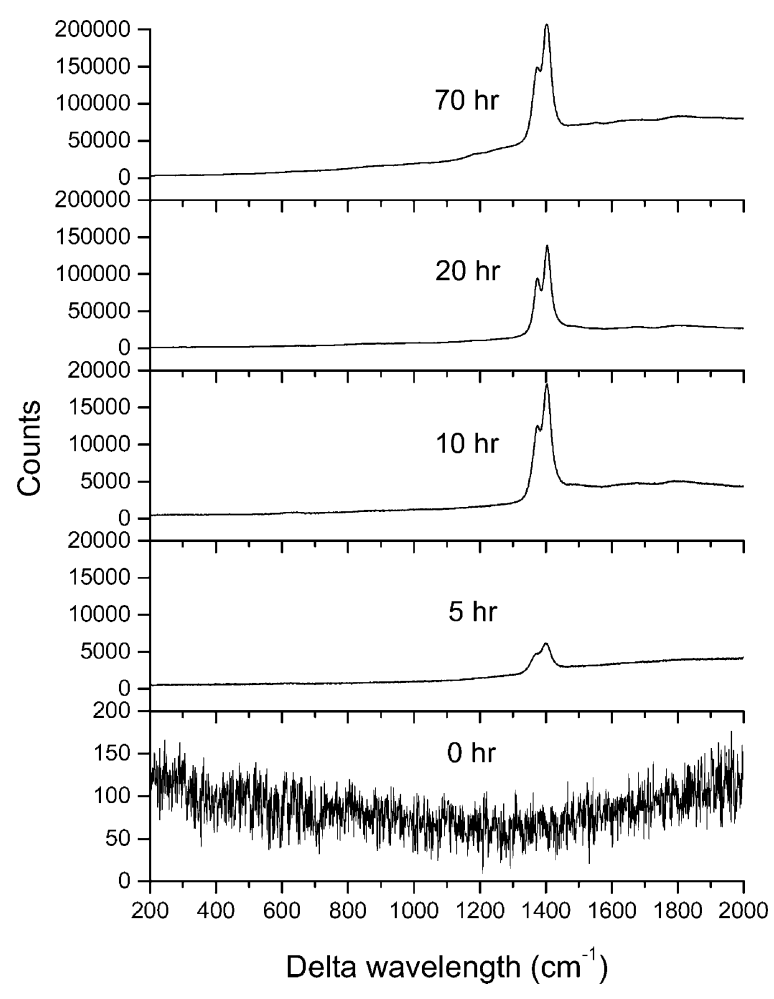

Fig. 13. The He-Ne laser excited Raman spectra of the anodized $\mathrm{Ti}-50 \mathrm{Al}$ after the exposure in air at $800^{\circ} \mathrm{C}$ for various durations. Anodization was carried out at $300 \mathrm{~V}$.

dizing voltage up to $400 \mathrm{~V}$, at which the parabolic rate constant $\mathrm{kp}$ can be reduced to about $1 / 600$ of that for as-homogenized Ti-50Al. The studies of Raman spectra of anodized $\mathrm{Ti}-50 \mathrm{Al}$ after cyclic oxidation indicate that the anodic film can slow down the formation of rutile and $\alpha-\mathrm{Al}_{2} \mathrm{O}_{3}$ on the surface during the oxidation, with the former oxide being more depressed than the latter one. The doping effect of phosphorus ions in titanium oxide is attributable to the improvement of high temperature oxidation of Ti-50Al.

\section{Acknowledgements}

The authors are pleased to acknowledge the financial support of this research provided by the National Science Council (NSC), Republic of China, under Grants Nos. NSC89-2623-7-002-010 and NSC89-2218-E002-071. 


\section{References}

[1] Dimiduk DM, Miracle DB, Ward CH. Mater Sci Technol 1992;8:367.

[2] Tetsui T, Ono S. Intermetall 1999;7:689.

[3] Kim YW. In: Johnson LA, Pope DP, Stiegler JO, editors. High temperature ordered intermetallic alloys IV, MRS proc. vol. 213. Pittsburgh (PA): MRS; 1991:777-94.

[4] Kim YW. JOM 1994;41:30.

[5] Kim BG, Kim GM, Kim CJ. Scripta Metall Mater 1995;33:1117.

[6] Shida Y, Anada H. Mater Trans JIM 1994;35:623.

[7] Huang BY, He YH, Wang JN. Intermetall 1999;7:881.

[8] Yoshida Y, Anada H. High temperature corrosion of advanced materials and protective coatings. New York: Elsevier Science; 1992.

[9] Hsu IC, Wu SK. Surf Coat Technol 1997;90:6.

[10] Shimizu T, Iikubo T, Isobe S. Mater Sci Eng 1992;A153:602.

[11] Taniguchi S, Shibata T, Takeuchi K. Mater Trans JIM 1991;32:299.

[12] Kim S, Yoon Y, Kim H, Park K. Mater Sci Technol 1998;14:435.

[13] Dong X, Zhihong Z, Xianghuai L, Shichang Z, Taniguchi S, Shibata T, Yamada T. Surf Coat Technol 1994;66:486.

[14] Yamaguchi M, Inui H. In: Darolia R, Lewandowski JJ, Martin PL, Miracle DB, Nathal MV, editors. Structural intermetallics. Warrendale (PA): TMS; 1993:127-42.

[15] Skowronski RP. J Am Ceram Soc 1994;77:1098.

[16] Stroosnijder MF, Zheng N, Quadakkers WJ, Hoffman R, Gil A, Lanza F. Oxid Metals 1996;46:19.

[17] Taniguchi S, Uesaki K, Zhu Y-C, Matsumoto Y, Shi-bata T. Mater Sci Eng 1999;A266:267.
[18] Boeing North American, Inc. US patent 5,695,827, 9 December, 1997.

[19] Yang MR, Wu SK. Mater Chem Phys 2000;65:144.

[20] Yang MR, Wu SK. Oxid Metals 2000;54:473.

[21] Ikematsu Y, Hanamura T, Morikawa H, Tanino M, Takamura J. In: Izumi O, editor. Proc. Int. Symp. on intermetallic compounds (JIMIS-6). Sendai (Japan): Japan Institute of Metals; 1991:191-5.

[22] Retallick WB, Brady MP, Humphrey DL. Intermetall 1998;6:335.

[23] Wernick S, Pinner R. The surface treatment and finishing of aluminum and its alloys. 4th ed. Teddington, UK: Robert Draper Ltd, 1972.

[24] Sibert ME. J Electrochem Soc 1963;110:65.

[25] Asam T. Surf Coat Technol 1999;116-119:310.

[26] Liu Z, Davis RJ. J Phys Chem 1994;98:1253.

[27] Albella JM, Montero I, Sanchez O, Martinez-Duart JM. J Electrochem Soc 1986;133:876.

[28] Henley VF. Anodic oxidation of aluminium and its alloys. 4th ed. New York: Pergamon Press; 1982.

[29] Dyer CK, Leach JSL. J Electrochem Soc 1978;125:1032.

[30] Porto SPS, Fleury PA, Damen TC. Phys Rev 1967; 154:522.

[31] Aminzadeh A. Appl Spectrosc 1997;51:817.

[32] Ohsaka T, Izumi F, Fujiki Y. J Raman Spectrosc 1978;7:321.

[33] Kofstad P. High temperature corrosion. New York: Elsevier Applied Science; 1988.

[34] Eppler RA, Spencer-Strong GH. J Am Ceram Soc 1969;52:263.

[35] Shannon RD, Pask JA. J Am Ceram Soc 1965;4:391.

[36] Eppler RA. J Am Ceram Soc 1987;79:C64.

[37] Schumacher G, Dettenwanger F, Schutze M, Iberl A, Reil D. Oxid Metals 2000;54:317. 